\title{
Hemoglobin as a possible biochemical index of hypertension-induced vascular damage
}

\author{
Yuji Shimizu*, Koichiro Kadota, Mio Nakazato, Yuko Noguchi, Jun Koyamatsu, Hirotomo Yamanashi, \\ Mako Nagayoshi, Shuichi Nagata, Kazuhiko Arima and Takahiro Maeda
}

\begin{abstract}
Background: We previously reported on the positive association of hemoglobin with hypertension and atherosclerosis. On the other hand, hepatocyte growth factor (HGF) has been evaluated as a possible biochemical index of hypertension-induced vascular damage. However, no studies have reported on a correlation between hemoglobin and HGF accounting for hypertension status.

Methods: A cross-sectional study of 1108 subjects (392 men and 716 women, 40-93 years old) who were undergoing a general checkup in 2014 was conducted.

Results: Multiple linear regression analysis adjustment for known cardiovascular risk factors showed no significant correlation between hemoglobin and HGF in non-hypertensive subjects, but a significant positive correlation in hypertensive subjects; $\beta$ (parameter estimate) $=0.3(p=0.975)$ for non-hypertensive men, $\beta=0.4(p=0.925)$ for nonhypertensive women, $\beta=32.7$ ( $p<0.001$ ) for hypertensive men, and $\beta=18.7(p=0.002)$ for hypertensive women.

Conclusion: We found a significant positive correlation between hemoglobin and HGF among hypertensive men and women. Like HGF, hemoglobin may be a useful indicator to evaluate hypertension-induced vascular damage. Since hemoglobin can easily be measured, these results support hemoglobin as an efficient tool to evaluate vascular damage induced by hypertension in daily medical practice.
\end{abstract}

\section{Background}

We reported independent positive associations of hemoglobin level with hypertension [1] and atherosclerosis [2] in both men and women. On the other hand, endothelial dysfunction may contribute to the increased vascular tone seen with hypertension [3]. Hemoglobin might therefore serve as an indicator of vascular damage induced by hypertension. Hepatocyte growth factor (HGF), which is known as an angiogenic growth factor $[4,5]$, plays an important role in endothelial maintenance (vascular maintenance) and endothelial repair (vascular repair). HGF prevents apoptosis of endothelial cells $[6,7]$ and suppresses xanthin oxidase activation [8] induced by hypoxia/reoxygenation. Furthermore, HGF promotes endothelial cell differentiation and increases endothelial progenitor cell migration and proliferation

\footnotetext{
* Correspondence: simizicyuu@yahoo.co.jp

Nagasaki University Graduate School of Biomedical Science, Nagasaki, Japan
}

[9]. However, other studies have reported HGF as a possible biochemical index of vascular damage due to hypertension [4, 10-14]. Another study reported a significant correlation between increased HGF concentration and carotid atherosclerosis [15]. These studies indicate that high plasma concentration of HGF indicates the presence of aggressive vascular remodeling, which results in atherosclerosis. Since HGF is constitutively produced by human bone marrow and indirectly promotes the growth of undifferentiated hematopoietic cells and erythroid progenitor cells [16], HGF level should correlate with hemoglobin, particularly when the bone marrow becomes activated by hypertension. Hemoglobin is an easily measured parameter; therefore, if it can substitute for HGF as a possible biochemical index of vascular damage due to hypertension $[4,10-14]$, it could serve as an efficient tool for blood pressure control in daily medical practice. Since the prevalence of hypertension might play an important role as a 
vascular impairment factor, the correlation between hemoglobin and HGF should account for hypertension status. However, no studies have reported a correlation between hemoglobin and HGF accounting for hypertension status. We therefore hypothesized that non-hypertensive men and women would show no significant correlation between hemoglobin and HGF, whereas a significant correlation would be found in subjects with hypertension.

To investigate these possible correlations, we conducted a cross-sectional study of 1108 subjects (392 men and 716 women, 40-93 years) who were undergoing general heath checkups in 2014.

\section{Subjects and methods Subjects}

The study was conducted during a medical screening program for members of the general population aged 40-99 years who were living in Goto city, Nagasaki Prefecture, Japan. After obtaining informed consent, 1555 Japanese subjects (536 men and 1019 women) were enrolled. Subjects without habitual status (drinking, smoking) data (1 male, 1 female) and/or without blood sample data (143 males, 301 females) were excluded. To avoid the influence of abnormal HGF values, one woman with extremely high HGF $(4825 \mathrm{pg} / \mathrm{mL})$ was excluded, leaving a total of 1108 subjects (392 men, 716 women) participating in the study. This study was approved by the Ethics Committee for Human Use of Nagasaki University (project registration number 14051404).

\section{Data collection and laboratory measurements}

Systolic and diastolic blood pressures at rest in a sitting position were recorded using a blood pressure measuring device (HEM-907; Omron, Kyoto, Japan) by trained technicians.

Height and weight in bare feet and light clothing were measured, and body mass index (BMI) was calculated as weight $(\mathrm{kg}) /(\text { height }(\mathrm{m}))^{2}$. Trained interviewers obtained information on smoking and drinking status. Fasting blood samples were collected in an EDTA-2K tube and a siliconized tube. Samples from the siliconized tube were centrifuged after blood coagulation, and the separated serum was collected. Samples from the EDTA-2K tube were used to measure hemoglobin using the sodium lauryl surfate (SLS)-hemoglobin method at SRL, Inc. (Tokyo, Japan). This method is recommended by the International Committee for Standardization in hematology. Serum triglyceride (TG), serum high-density lipoprotein (HDL) cholesterol, serum low-density lipoprotein (LDL) cholesterol, serum aspartate aminotransferase (AST), serum $\gamma$-glutamyltranspeptidase $\left(\gamma\right.$-GTP), hemoglobin $(\mathrm{Hb}) \mathrm{A}_{1 \mathrm{C}}$, and serum creatinine were measured using standard laboratory procedures at SRL, Inc. (Tokyo, Japan). To measure HGF, serum samples were diluted fourfold with specific Bio-Plex sample diluents. HGF concentration was determined using a fluorescent bead-based immunosorbent assay on a suspension array. Glomerular filtration rate (GFR) was estimated using an established method with three variations that were recently proposed by a working group of the Japanese Chronic Kidney Disease Initiative [17]. According to this adaptation, GFR $\left(\mathrm{mL} / \mathrm{min} / 1.73 \mathrm{~m}^{2}\right)=194 \times($ serum creatinine $($ enzyme method $))^{-1.094} \times(\text { age })^{-0.287} \times(0.739$ for women $)$. Hypertension was defined as a systolic blood pressure $\geq 140 \mathrm{mmHg}$ and/or a diastolic blood pressure $\geq 90 \mathrm{mmHg}$.

\section{Statistical analysis}

Sex-specific models were conducted. Difference in mean \pm standard deviation (SD) values, the prevalence of potential confounding factors, and $p$ values by hypertension status were calculated. Simple correlation coefficients of HGF and other variables stratified by hypertension were calculated. Simple and multiple linear regression analyses stratified by hypertension were performed to evaluate the correlation between hemoglobin and HGF. Probability values less than 0.05 were considered to indicate statistical significance. All statistical analyses were performed with the SAS system for Windows (version 9.3; SAS Inc., Cary, NC).

\section{Results}

Among the study population, 512 individuals (198 men and 314 women) were recognized as having hypertension. Sex-specific characteristics of the study population by hypertension status are shown in Table 1 . Both men and women subjects with hypertension showed significantly higher levels of hemoglobin and BMI than subjects without hypertension. The mean \pm SD values of hemoglobin and BMI for non-hypertensive and hypertensive men were $14.5 \pm 1.3 \mathrm{~g} / \mathrm{dL}, 22.7 \pm 2.7 \mathrm{~kg} / \mathrm{m}^{2}$ and $14.7 \pm 1.2 \mathrm{~g} / \mathrm{dL}, 23.7 \pm 3.1 \mathrm{~kg} / \mathrm{m}^{2}(p=0.025$ and $p<0.001)$, respectively; and the corresponding values for nonhypertensive and hypertensive women were $12.9 \pm 1.1 \mathrm{~g} / \mathrm{dL}$, $22.3 \pm 3.5 \mathrm{~kg} / \mathrm{m}^{2}$ and $13.2 \pm 1.2 \mathrm{~g} / \mathrm{dL}, 23.1 \pm 3.3 \mathrm{~kg} / \mathrm{m}^{2}$ ( $p=0.003$ and $p=0.004)$, respectively.

The simple correlation coefficients of HGF and other variables stratified by hypertension status are shown in Table 2. In non-hypertensive men and women, no significant correlation between hemoglobin and HGF was seen, whereas a significant positive correlation was seen among subjects with hypertension. This was also seen from simple linear regression analysis (Fig. 1). From multiple linear regression analysis adjustment for known cardiovascular risk factors, significant positive correlation between hemoglobin and HGF was observed in both men $(\beta$ (parameter estimate $)=32.7, p<0.001)$ and 
Table 1 Sex-specific characteristics of the study population by hypertension status

\begin{tabular}{|c|c|c|c|c|c|c|}
\hline & \multicolumn{3}{|l|}{ Men } & \multicolumn{3}{|l|}{ Women } \\
\hline & \multicolumn{3}{|l|}{ Hypertension } & \multicolumn{3}{|l|}{ Hypertension } \\
\hline & $(-)$ & $(+)$ & $p$ & $(-)$ & $(+)$ & $p$ \\
\hline No. of cases & 194 & 198 & & 402 & 314 & \\
\hline Age & $69.4 \pm 9.4$ & $69.9 \pm 9.1$ & 0.612 & $67.3 \pm 9.7$ & $72.9 \pm 8.9$ & $<0.001$ \\
\hline Hepatocyte growth factor (HGF), pg/mL & $279.7 \pm 126.8$ & $284.6 \pm 150.9$ & 0.730 & $239.6 \pm 88.7$ & $256.1 \pm 119.8$ & 0.035 \\
\hline Hemoglobin (Hb), g/dL & $14.5 \pm 1.3$ & $14.7 \pm 1.2$ & 0.025 & $12.9 \pm 1.1$ & $13.2 \pm 1.2$ & 0.003 \\
\hline Systolic blood pressure, mmHg & $123 \pm 10$ & $151 \pm 13$ & $<0.001$ & $124 \pm 10$ & $153 \pm 14$ & $<0.001$ \\
\hline Diastolic blood pressure, $\mathrm{mmHg}$ & $76 \pm 9$ & $91 \pm 10$ & $<0.001$ & $74 \pm 9$ & $86 \pm 11$ & $<0.001$ \\
\hline Body mass index (BMI), kg/m² & $22.7 \pm 2.7$ & $23.7 \pm 3.1$ & $<0.001$ & $22.3 \pm 3.5$ & $23.1 \pm 3.3$ & 0.004 \\
\hline Curent drinker, \% & 53.1 & 63.6 & 0.034 & 17.7 & 14.0 & 0.188 \\
\hline Curent smoker, \% & 16.5 & 18.2 & 0.660 & 3.7 & 1.6 & 0.085 \\
\hline Serum HDL cholesterol, mg/dL & $56 \pm 15$ & $57 \pm 14$ & 0.588 & $63 \pm 14$ & $61 \pm 14$ & 0.049 \\
\hline Serum LDL cholesterol, mg/dL & $109 \pm 28$ & $111 \pm 29$ & 0.517 & $120 \pm 28$ & $124 \pm 29$ & 0.052 \\
\hline Serum triglyceride (TG), mg/dL & $108 \pm 72$ & $122 \pm 111$ & 0.144 & $99 \pm 53$ & $114 \pm 62$ & $<0.001$ \\
\hline Serum aspartate transaminase (AST), IU/L & $25 \pm 9$ & $26 \pm 11$ & 0.096 & $22 \pm 6$ & $23 \pm 7$ & 0.127 \\
\hline Serum $\gamma$-glutamyltranspeptidase ( $\gamma$-GTP), IU/L & $34 \pm 28$ & $51 \pm 79$ & 0.004 & $23 \pm 19$ & $21 \pm 14$ & 0.073 \\
\hline Hemoglobin A1c (HbA1c), \% & $5.6 \pm 0.5$ & $5.8 \pm 0.9$ & 0.109 & $5.6 \pm 0.4$ & $5.7 \pm 0.5$ & 0.137 \\
\hline Glomerular filtration rate (GFR), mL/min/1.73 m² & $69.1 \pm 15.2$ & $69.4 \pm 13.8$ & 0.847 & $68.8 \pm 14.1$ & $66.5 \pm 13.6$ & 0.026 \\
\hline
\end{tabular}

women $(\beta=18.7, p=0.002)$ with hypertension (Tables 3 and 4).

\section{Discussion}

A major finding of this study was a significant positive correlation between hemoglobin and HGF among hypertensive men and women subjects, but not among non-hypertensive subjects.

The association between hypertension and endothelial dysfunction is bidirectional. In a state of hypertension, oxidative stress increases due to increased NADH/ NADPH oxidase activation, while oxidative stress

Table 2 Sex-specific simple correlation coefficient of hepatocyte growth factor (HGF) and other variables

\begin{tabular}{|c|c|c|c|c|c|c|c|c|}
\hline & \multicolumn{4}{|l|}{ Men } & \multicolumn{4}{|c|}{ Women } \\
\hline & \multicolumn{2}{|c|}{ Hypertension (-) } & \multicolumn{2}{|c|}{ Hypertension (+) } & \multicolumn{2}{|c|}{ Hypertension (-) } & \multicolumn{2}{|c|}{ Hypertension (+) } \\
\hline & $r$ & $p$ & $r$ & $p$ & $r$ & $p$ & $r$ & $p$ \\
\hline Age & 0.11 & 0.123 & -0.16 & 0.020 & 0.15 & 0.003 & 0.10 & 0.091 \\
\hline Systolic blood pressure & 0.19 & 0.009 & -0.02 & 0.737 & 0.07 & 0.156 & -0.02 & 0.720 \\
\hline Diastolic blood pressure & 0.18 & 0.013 & 0.08 & 0.250 & -0.06 & 0.269 & 0.03 & 0.589 \\
\hline Body mass index (BMI) & 0.03 & 0.638 & 0.33 & $<0.001$ & 0.16 & 0.001 & 0.13 & 0.027 \\
\hline Drinking status & -0.03 & 0.642 & -0.01 & 0.936 & -0.06 & 0.257 & 0.05 & 0.370 \\
\hline Smoking status & 0.14 & 0.059 & 0.12 & 0.086 & -0.004 & 0.937 & 0.06 & 0.301 \\
\hline Serum HDL cholesterol & -0.12 & 0.107 & -0.08 & 0.237 & -0.14 & 0.004 & -0.08 & 0.140 \\
\hline Serum LDL cholesterol & -0.07 & 0.346 & -0.09 & 0.196 & -0.07 & 0.146 & -0.10 & 0.081 \\
\hline Serum triglycerides (TG) & 0.04 & 0.618 & 0.09 & 0.187 & 0.01 & 0.845 & 0.04 & 0.510 \\
\hline Serum aspartate transaminase (AST) & 0.01 & 0.888 & 0.25 & $<0.001$ & 0.02 & 0.647 & 0.11 & 0.047 \\
\hline Serum $\gamma$-glutamyltranspeptidase $(\gamma-G T P)$ & 0.03 & 0.705 & 0.26 & $<0.001$ & -0.01 & 0.834 & 0.11 & 0.043 \\
\hline Hemoglobin A1c (HbA1c) & 0.11 & 0.117 & 0.05 & 0.507 & 0.11 & 0.031 & 0.17 & 0.002 \\
\hline Glomerular filtration rate (GFR) & -0.04 & 0.542 & 0.09 & 0.223 & -0.09 & 0.074 & -0.01 & 0.869 \\
\hline Hemoglobin (Hb) & -0.01 & 0.905 & 0.28 & $<0.001$ & -0.02 & 0.636 & 0.17 & 0.003 \\
\hline
\end{tabular}




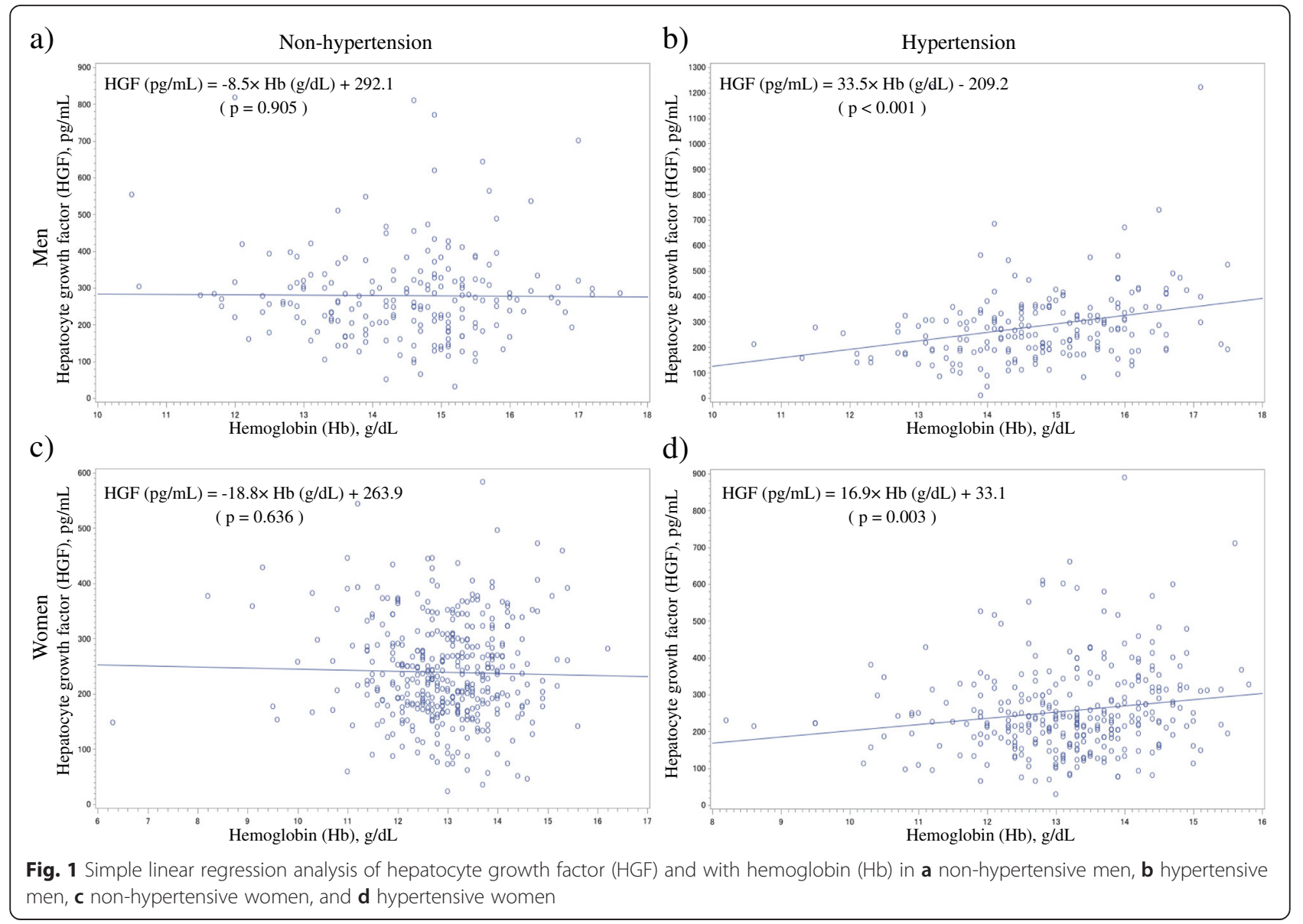

Table 3 Multiple linear regression analysis of hepatocyte growth factor (HGF) with relevant factors adjusted for confounding factors among men

\begin{tabular}{|c|c|c|c|c|c|c|}
\hline & \multicolumn{3}{|c|}{ Hypertension (-) } & \multicolumn{3}{|c|}{ Hypertension (+) } \\
\hline & $\beta$ & $95 \% \mathrm{Cl}$ & $p$ & $\beta$ & $95 \% \mathrm{Cl}$ & $p$ \\
\hline No. of participants & & 194 & & & 198 & \\
\hline Age & 1.3 & $(-0.9,3.5)$ & 0.255 & -0.3 & $(-3.0,2.4)$ & 0.815 \\
\hline Systolic blood pressure & 0.6 & $(-1.9,3.2)$ & 0.620 & 0.1 & $(-1.5,1.7)$ & 0.923 \\
\hline Diastolic blood pressure & 2.4 & $(-0.5,5.3)$ & 0.110 & -1.1 & $(-3.5,1.4)$ & 0.396 \\
\hline Body mass index (BMI) & -1.7 & $(-9.5,6.1)$ & 0.668 & 11.2 & $(3.9,18.5)$ & 0.003 \\
\hline Drinking status & -4.0 & $(-13.8,5.7)$ & 0.413 & -5.5 & $(-14.8,3.9)$ & 0.250 \\
\hline Smoking status & 25.8 & $(-3.2,54.9)$ & 0.081 & 11.3 & $(-20.5,43.2)$ & 0.484 \\
\hline Serum HDL cholesterol & -0.9 & $(-2.4,0.7)$ & 0.276 & -0.4 & $(-1.9,1.2)$ & 0.663 \\
\hline Serum LDL cholesterol & -0.4 & $(-1.1,0.2)$ & 0.195 & -0.4 & $(-1.2,0.3)$ & 0.259 \\
\hline Serum triglycerides (TG) & -0.04 & $(-0.3,0.3)$ & 0.800 & -0.2 & $(-0.4,0.03)$ & 0.091 \\
\hline Serum aspartate aminotransferase (AST) & -0.4 & $(-2.7,2.0)$ & 0.757 & 1.6 & $(-0.7,3.8)$ & 0.170 \\
\hline Serum $\gamma$-glutamyltranspeptidase ( $\gamma$-GTP) & 0.2 & $(-0.6,1.0)$ & 0.602 & 0.4 & $(0.04,0.8)$ & 0.029 \\
\hline Hemoglobin A1c (HbA1c) & 14.1 & $(-20.8,48.9)$ & 0.427 & 6.5 & $(-16.8,29.9)$ & 0.582 \\
\hline Glomerular filtration rate (GFR) & 0.1 & $(-1.2,1.4)$ & 0.882 & 0.1 & $(-1.4,1.6)$ & 0.906 \\
\hline Hemoglobin $(\mathrm{Hb})$ & 0.3 & $(-15.9,16.4)$ & 0.975 & 32.7 & $(14.4,51.0)$ & $<0.001$ \\
\hline
\end{tabular}

Drinking status (never drinker, former drinker, current drinker (<23 g/week, 23-45 g/week, 46-68 g/week, $\geq 69$ g/week)), smoking status (never smoker, former smoker, current smoker) 
Table 4 Multiple linear regression analysis of hepatocyte growth factor (HGF) with relevant factors adjusted for confounding factors among women

\begin{tabular}{|c|c|c|c|c|c|c|}
\hline & \multicolumn{3}{|c|}{ Hypertension (-) } & \multicolumn{3}{|c|}{ Hypertension (+) } \\
\hline & $\beta$ & $95 \% \mathrm{Cl}$ & $p$ & $\beta$ & $95 \% \mathrm{Cl}$ & $p$ \\
\hline No. of participants & & 402 & & & 314 & \\
\hline Age & 1.1 & $(-0.02,2.2)$ & 0.055 & 2.6 & $(0.8,4.5)$ & 0.006 \\
\hline Systolic blood pressure & 0.4 & $(-0.6,1.5)$ & 0.418 & -0.7 & $(-1.7,0.3)$ & 0.181 \\
\hline Diastolic blood pressure & -0.5 & $(-1.7,0.8)$ & 0.450 & 0.9 & $(-0.6,2.3)$ & 0.231 \\
\hline Body mass index (BMI) & 3.7 & $(1.0,6.3)$ & 0.007 & 1.5 & $(-2.7,5.8)$ & 0.482 \\
\hline Drinking status & -1.8 & $(-8.0,4.4)$ & 0.562 & 4.3 & $(-6.3,15.0)$ & 0.426 \\
\hline Smoking status & 11.0 & $(-9.6,31.6)$ & 0.293 & 25.2 & $(-15.2,65.5)$ & 0.220 \\
\hline Serum HDL cholesterol & -0.8 & $(-1.5,-0.1)$ & 0.023 & -1.0 & $(-2.0,0.05)$ & 0.061 \\
\hline Serum LDL cholesterol & -0.2 & $(-0.6,0.1)$ & 0.129 & -0.4 & $(-0.8,0.1)$ & 0.124 \\
\hline Serum triglycerides (TG) & -0.1 & $(-0.3,0.04)$ & 0.122 & -0.1 & $(-0.3,0.2)$ & 0.598 \\
\hline Serum aspartate aminotransferase (AST) & -0.3 & $(-1.9,1.2)$ & 0.652 & 1.4 & $(-0.5,3.3)$ & 0.146 \\
\hline Serum $\gamma$-glutamyltranspeptidase ( $\gamma$-GTP) & 0.05 & $(-0.4,0.5)$ & 0.851 & 0.5 & $(-0.5,1.5)$ & 0.353 \\
\hline Hemoglobin A1c (HbA1c) & 11.5 & $(-10.3,33.4)$ & 0.301 & 41.7 & $(16.6,66.9)$ & 0.001 \\
\hline Glomerular filtration rate (GFR) & -0.2 & $(-0.9,0.5)$ & 0.627 & 0.3 & $(-0.7,1.4)$ & 0.525 \\
\hline Hemoglobin (Hb) & 0.4 & $(-7.5,8.3)$ & 0.925 & 18.7 & $(6.7,30.7)$ & 0.002 \\
\hline
\end{tabular}

Drinking status (never drinker, former drinker, current drinker (<23 g/week, 23-45 g/week, 46-68 g/week, $\geq 69$ g/week)), smoking status (never smoker, former smoker, current smoker)

inactivates nitric monoxide (NO), which is known as an endothelial-dependent vasodilation factor, by causing injury to endothelial cells, resulting in increased vasoconstriction [18]. Hypertension is therefore maintained. In addition to this mechanism, endothelial dysfunction causes reduced NO production, and increased endothelial-dependent vasoconstriction factors such as endothelin, angiotensin II, and thromboxane are also observed in hypertension [19]. The number of growth factors in circulating blood was reported to increase when complications consisting of hypertension arose in response to vascular endothelial cell damage [20]. Additionally, HGF is reported to be produced by polynuclear leukocytes [21], vascular smooth muscle cells, endothelial cells in humans in vivo [22], and human osteoblasts in vitro [23], and unlike most known growth factors, HGF acts specifically on the endothelium and does not promote the growth of smooth muscle cells [5]. Furthermore, one study reported that the overexpression of HGF in smooth muscle cells can be beneficial for promoting endothelial cell differentiation and increasing endothelial progenitor cell migration and proliferation [9]. However, human endothelial progenitor cells (CD34positive cells) are reported to differentiate into not only endothelial cells but also into foam cells, which are a contributing factor in the development of atherosclerosis [24]. Other studies have reported the presence of CD34-positive cells in human atherosclerotic lesions $[25,26]$. Furthermore, increased HGF concentration significantly correlates with carotid atherosclerosis
[15]. Therefore, even though HGF has a beneficial effect on vascular endothelial repair, subjects with a high plasma HGF concentration likely have a high risk of atherosclerosis (endothelial dysfunction). Additionally, HGF is reported to indirectly promote the growth of undifferentiated hematopoietic cells (CD34-positive cells) and erythroid progenitor cells (source of hemoglobin) [16]. Also, because osteoblasts regulate the production of hematopoietic stem cells in the bone marrow [27, 28], and HGF is reported to be produced by osteoblasts [23], high levels of plasma HGF and hemoglobin might also indicate high activity of the bone marrow. Since hematopoietic stem cells derived from the bone marrow play a major role in vascular homeostasis [29-31], and other studies have reported that hemoglobin plays an important role in the progression of atherosclerosis [32, 33], hemoglobin level significantly correlates with HGF when the bone marrow is activated by endothelial damage induced by hypertension. In our previous study, we reported that hemoglobin levels in both men and women are positively associated with hypertension [1] and atherosclerosis [2]. Other studies identified HGF as a possible biochemical index of hypertensioninduced vascular damage $[4,10-14]$. These studies partly support the abovementioned mechanisms. A possible mechanism underlying the observed correlation between hemoglobin and HGF in hypertensive subjects is summarized in Fig. 2.

Our findings should be interpreted with some caution. Although hemoglobin, which might act as a marker of 


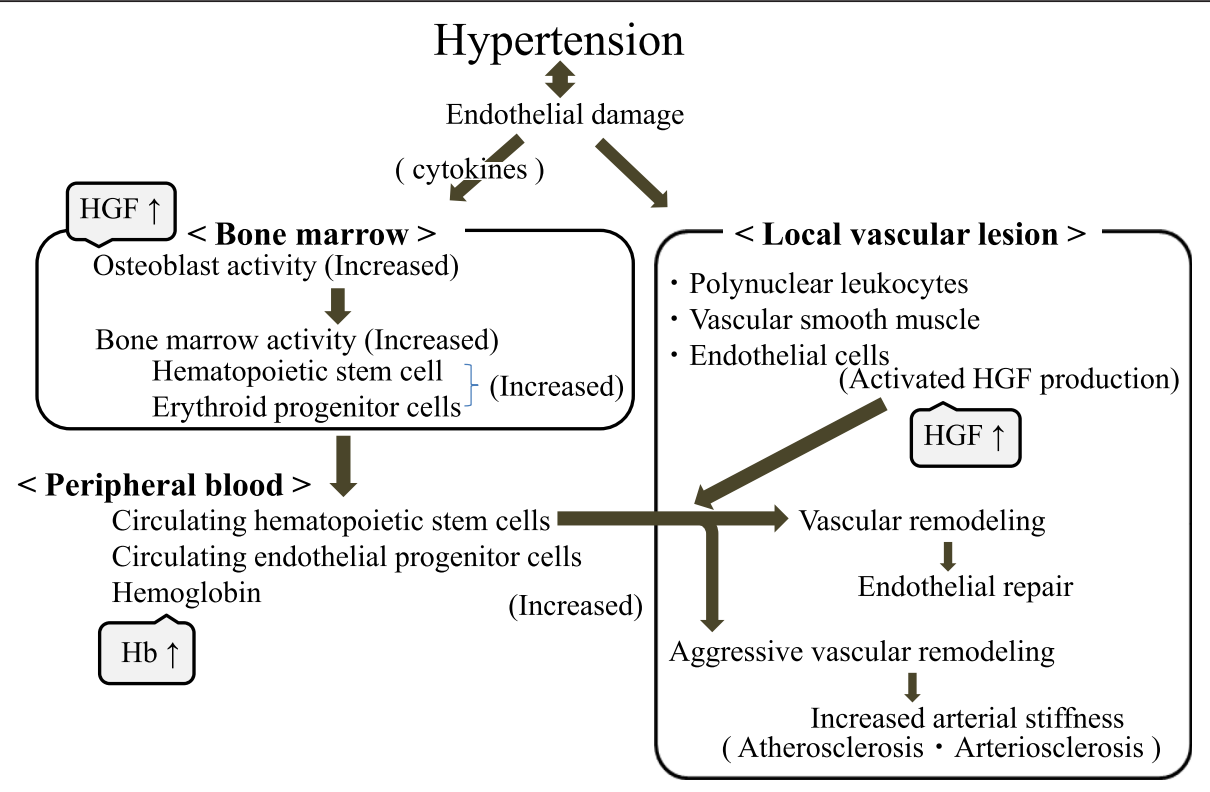

Fig. 2 Possible mechanism of endothelial dysfunction and repair in relation to hypertension

bone marrow activity, showed a significant positive correlation with HGF, we were not able to evaluate the influence of hematopoietic stem cells. Further investigations using hematopoietic stem cell data are necessary. Finally, since this was a cross-sectional study, no causal relationships were able to be established.

\section{Conclusion}

In conclusion, an independent positive correlation between hemoglobin and HGF was observed in hypertensive Japanese males and females. Since HGF is useful for evaluating hypertension-induced vascular damage, hemoglobin may be beneficial in this regard as well. Since hemoglobin is easily measured, the results indicate that it could serve as an efficient tool to evaluate vascular damage induced by hypertension in daily medical practice.

\section{Abbreviations}

AST: aspartate aminotransferase; BMI: body mass index; GFR: glomerular filtration rate; $\mathrm{Hb}$ : hemoglobin; HGF: hepatocyte growth factor;

SD: standard deviation; SLS: sodium lauryl surfate; $\beta$ : parameter estimate; Y-GTP: $\gamma$-glutamyltranspeptidase.

\section{Competing interests}

The authors declare that they have no competing interests.

\section{Authors' contributions}

YS designed the study, performed the statistical analyses, interpreted the data, and drafted the manuscript or revised it. MN, KK, YN, KA, and JK assisted with the design of the study, were involved in the data collection, and checked the manuscript. $\mathrm{HY}, \mathrm{SN}, \mathrm{MN}, \mathrm{KA}$, and KK participated in the study concept and checked the manuscript. TM was the general coordinator and also designed the study. All authors have read and approved submission of the manuscript, and that material in the manuscript has not been published and is not being considered for publication elsewhere in whole or in part in any language except as an abstract. The person in acknowledgement has been seen and approved mentions of his name in the article.

\section{Acknowledgements}

This work was supported by the Grants-in-Aid for Scientific Research from the Japan Society for the Promotion of Science (No. 25440255, No. 15K07243).

Received: 20 November 2015 Accepted: 15 January 2016 Published online: 28 January 2016

\section{References}

1. Shimizu Y, Nakazato M, Sekita T, Kadota K, Arima K, Yamasaki H, et al. Association between the hemoglobin levels and hypertension in relation to BMI status in a rural Japanese population: the Nagasaki Islands study. Intern Med. 2014;53:435-40

2. Shimizu Y, Nakazato M, Sekita T, Kadota K, Yamasaki H, Takamura N, et al. Association between hemoglobin levels and arterial stiffness for general Japanese population in relation to body mass index status: the Nagasaki Islands study. Geriatr Gerontol Int. 2014;14:811-8.

3. Endemann DH, Schiffrin EL. Endothelial dysfunction. J Am Soc Nephrol. 2004;15:1983-92.

4. Nakamura Y, Morishita R, Nakamura S, Aoki M, Moriguchi A, Matsumoto K, et al. A vascular modulator, hepatocyte growth factor, is associated with systolic pressure. Hypertension. 1996;28:409-13.

5. Nakamura Y, Morishita R, Higaki J, Kida I, Aoki M, Moriguchi A, et al. Hepatocyte growth factor is a novel member of the endothelium-specific growth factors: additive stimulatory effect of hepatocyte growth factor with basic fibroblast growth factor but not with vascular endothelial growth factor. J Hypertens. 1996;14:1067-72.

6. Wang X, Zhou Y, Kim HP, Song R, Zarnegar R, Ryter SW, et al. Hepatocyte growth factor protects against hypoxia/reoxygenation-induced apoptosis in endothelial cells. J Biol Chem. 2004;279:5237-43.

7. Nakagami H, Morishita R, Yamamoto K, Taniyama Y, Aoki M, Yamasaki K, et al. Hepatocyte growth factor prevents endothelial cell death through inhibition of bax translocation from cytosol to mitochondrial membrane. Diabetes. 2002:51:2604-11.

8. Zhang Y, Hu S, Chen Y. Hepatocyte growth factor suppresses hypoxia/ reoxygenation-induced $\mathrm{XO}$ activation in cardiac microvascular endothelial cells. Heart Vessels. 2015;30:534-44.

9. Zhu G, Huang L, Song M, Yu Z, Wu X, Zhao X, et al. Over-expression of hepatocyte growth factor in smooth muscle cells regulates endothelial 
progenitor cells differentiation, migration and proliferation. Int J Cardiol. 2010;138:70-80.

10. Nishimura M, Ushiyama M, Ohtsuka K, Nishida M, Inoue N, Matsumuro A, et al. Serum hepatocyte growth factor as a possible indicator of vascular lesions. J Clin Endocrinol Metab. 1999;84:2475-80.

11. Morishita R, Nakamura S, Hayashi S, Aoki M, Matsushita H, Tomita N, et al. Contribution of a vascular modulator, hepatocyte growth factor (HGF), to the pathogenesis of cardiovascular disease. J Atheroscler Thromb. 1998:4:128-34.

12. Morishita R, Moriguchi A, Higaki J, Ogihara T. Hepatocyte growth factor (HGF) as a potential index of severity of hypertension. Hypertens Res. 1999;22:161-7.

13. Nishimura M, Ushiyama M, Maruyama Y, Mabuchi H, Takahashi H, Yoshimura M. Association of human hepatocyte growth factor with hemodialysis hypotension. Hypertens Res. 2000;23:581-6.

14. Hayashi Y, Saitoh S, Takagi S, Tuchihashi K, Miura T, Shimamoto K. Hepatocyte growth factor and 24-hour ambulatory blood pressure monitoring. Hypertens Res. 2002;25:655-60.

15. Kawamoto R, Oka Y, Yoshida O, Takagi Y. Significance of serum circulating hepatocyte growth factor in the development of carotid atherosclerosis. J Atheroscler Thromb. 2003;10:154-9.

16. Takai K, Hara J, Matsumoto K, Hosoi G, Osugi Y, Tawa A, et al. Hepatocyte growth factor is constitutively produced by human bone marrow stromal cells and indirectly promotes hematopoiesis. Blood. 1997;89:1560-5.

17. Imai E. Equation for estimating GFR from creatinine in Japan. Nihon Rinsho. 2008;66:1725-9 [Article in Japanese].

18. Dohi Y. Hypertension and oxidative stress. Nagoya Med J. 2010;51:153-8 [Article in Japanese].

19. Higashi Y, Sueda T, Yoshizumi M. Role of angiotensin II-related oxidative stress and nitric oxide in endothelial function in hypertension. J Jpn Coll Angiol. 2003;43:47-52 [Article in Japanese].

20. Nakamura S, Moriguchi A, Morishita R, Aoki M, Yo Y, Hayashi S, et al. A novel vascular modulator, hepatocyte growth factor (HGF), as a potential index of the severity of hypertension. Biochem Biophys Res Commun. 1998;242:238-43.

21. Sakaguchi H, Seki S, Tsubouchi H, Daikuhara Y, Niitani Y, Kobayashi K. Ultrastructural location of human hepatocyte growth factor in human liver. Hepatology. 1994;19:1157-63.

22. Nakamura Y, Morishita R, Higaki J, Kida I, Aoki M, Moriguchi A, et al. Expression of local hepatocyte growth factor system in vascular tissues. Biochem Biophys Res Commum. 1995;215:483-8.

23. Taichman R, Reilly M, Verma R, Ehrenman K, Emerson S. Hepatocyte growth factor is secreted by osteoblasts and cooperatively permits the survival of haematopoietic progenitors. Br J Haematol. 2001;112:438-48.

24. Daub K, Langer $\mathrm{H}$, Seizer $P$, Stellos K, May AE, Goyal P, et al. Platelets induce differentiation of human CD34+ progenitor cells into foam cells and endothelial cells. FASEB J. 2006;20:2559-61.

25. Torsney E, Mandal K, Halliday A, Jahangiri M, Xu Characterisation of progenitor cells in human atherosclerotic vessels. Atherosclerosis. 2007:191:259-64.

26. Moreno PR, Purushothaman KR, Fuster V, Echeverri D, Truszczynska H, Sharma SK, et al. Plaque neovascularization is increased in ruptured atherosclerotic lesions of human aorta: implications for plaque vulnerability. Circulation. 2004;110:2032-8.

27. Calvi LM, Adams GB, Weibrecht KW, Weber JM, Olson DP, Knight MC, et al. Osteoblastic cells regulate the haematopoietic stem cell niche. Nature. 2003:425:841-6.

28. Zhang J, Niu C, Ye L, Huang H, He X, Tong WG, et al. Identification of the haematopoietic stem cell niche and control of the niche size. Nature. 2003;425:836-41.

29. Takakura N, Watanabe T, Suenobu S, Yamada Y, Noda T, Ito Y, et al. A role for hematopoietic stem cells in promoting angiogenesis. Cell. 2000;102:199-209.

30. Yamada Y, Takakura N. Physiological pathway of differentiation of hematopoietic stem cell population into mural cells. J Exp Med. 2006;203:1055-65.

31. Shi Q, Rafii S, Wu HM, Wijelath ES, Yu C, Ishida A, et al. Evidence for circulating bone marrow-derived endothelial cells. Blood. 1998;92:362-7.

32. Jeney V, Balla G, Balla J. Red blood cell, hemoglobin and heme in the progression of atherosclerosis. Front Physiol. 2014;5:379.

33. Nagy E, Eaton JW, Jeney V, Soares MP, Varga Z, Galajda Z, et al. Red cells, hemoglobin, heme, iron, and atherogenesis. Arterioscler Thromb Vasc Biol. 2010;30:1347-53.

\section{Submit your next manuscript to BioMed Central and we will help you at every step:}

- We accept pre-submission inquiries

- Our selector tool helps you to find the most relevant journal

- We provide round the clock customer support

- Convenient online submission

- Thorough peer review

- Inclusion in PubMed and all major indexing services

- Maximum visibility for your research

Submit your manuscript at www.biomedcentral.com/submit
C Biomed Central 